\title{
An Innovative Design of Anti-Animal Trash Bin to Solve Human-Macaque Conflict Issue
}

\author{
Kamarul Hambali, Noorsuhaily Ali, Nor Hizami Hassin, Muhamad Azahar Abas, Mohamad \\ Najmi Masri, Mazlan Mohamed, Aainaa Amir, Muhammad Khairul Arif Ahamad
}

\begin{abstract}
Nowadays, conflict between humans and macaques has become a major issue that is frequently reported. Among the conflicts that often performed by the long-tailed macaques are littering, damaging facilities, breaking into human areas, messing up trash bins, disturbing people and stealing. Overall, food is a major source of conflict between humans and macaques. The food from the trash bins found in residential, and recreation areas are the attraction of long-tailed macaques to bring the conflict. Long-tailed macaques able to easily open the secured trash bins for scavenging for food. Therefore, anti-animal trash bin was designed to solve this problem. This anti-animal trash bin has been specially designed with an opening and locking mechanism that prevents the long-tailed macaques from opening the trash. The drawing of anti-animal trash bin was using SolidWork software to show its design features. In addition, a questionnaire was also conducted to obtain feedback from the users about the product.
\end{abstract}

Index Terms: Anti-animal trash bin, design, human-macaque conflict, innovative.

\section{INTRODUCTION}

Long-tailed macaques or known by its scientific name Macaca fascicularis are the most widespread non-human primate species [1], [2] as its distribution can be found throughout Peninsular Malaysia including Sabah and Sarawak, as well as throughout Southern Asia; lower north of Thailand, Myanmar, Southern Laos, Cambodia, Vietnam, Sumatra, Java and the Philippines [3]-[5]. These long-tailed macaque is an extremely high-ability animal in adaptation to the environment and an opportunistic omnivore animal [1]. As a result, long-tailed macaques are easily found in a wide variety of areas and habitats, especially in lowland, coastal and even urban areas [6]. According to [7], long-tailed macaques living in anthropogenic habitats not only choose food that is made up of plant and animal sources, but they also choose food waste dumped into the trash as their main

Revised Version Manuscript Received on September 16, 2019.

Kamarul Hambali, Faculty of Earth Science, Universiti Malaysia Kelantan, 17600 Jeli, Kelantan, Malaysia.

(Email: kamarul@umk.edu.my)

Noorsuhaily Ali, MARA Junior Science College, Terendak Camp, 76200 Melaka, Malaysia.

Nor Hizami Hassin, Faculty of Earth Science, Universiti Malaysia Kelantan, 17600 Jeli, Kelantan, Malaysia.

Muhamad Azahar Abas, Faculty of Earth Science, Universiti Malaysia Kelantan, 17600 Jeli, Kelantan, Malaysia.

Mohamad Najmi Masri, Faculty of Bioengineering and Technology, Universiti Malaysia Kelantan, 17600 Jeli, Kelantan, Malaysia.

Mazlan Mohamed, Faculty of Bioengineering and Technology, Universiti Malaysia Kelantan, 17600 Jeli, Kelantan, Malaysia.

Aainaa Amir, Faculty of Earth Science, Universiti Malaysia Kelantan, 17600 Jeli, Kelantan, Malaysia. Universiti Malaysia Kelantan, 17600 Jeli, Kelantan, Malaysia.
Muhammad Khairul Arif Ahamad, Faculty of Earth Science,

food source.

Increasing human population has led to the destruction of the natural habitat of long-tailed macaques, worsening the human-macaque conflicts. Not only that, the disposal of unmanaged food waste and agricultural activities close to the

long-tailed macaques habitat has also made them dependent on the source of the food (habituation) and this is also a factor in the conflict between humans and long-tailed macaques [7]. For this reason, long-tailed macaques that live near the edge of the forest are often labeled as pests [8]. In addition, the tendency for humans to feed wild long-tailed macaques have also caused them to become habituation with humans and this encourages them to find food around human settlements by messing up trash bin and causing unpleasant sight [9] and potentially spreading disease [10].

Long-tail macaques are intelligent animals, they can feed on a variety of techniques they learn from experience and self-learning [11]. Therefore, in this manuscript we want to show the drawing of an anti-animal trash bin using SolidWork software to show its design features that prevent the long-tailed macaques from opening it. In addition, a survey was also conducted to get feedback from users on the anti-animal trash bin.

\section{METHODOLOGY}

\section{A. Product design}

An anti-animal trash bin model was designed at Universiti Malaysia Kelantan using SolidWork software to demonstrate the product's features.

\section{B. Questionnaire survey}

A survey using a structured questionnaire was conducted around the Terendak Camp, Malacca to get feedback from a total of 100 respondents who have used the product. Five anti-animal trash bins have been placed around the area Terendak Camp was chosen because there is a very serious long-tailed macaque's disturbance.

\section{RESULTS AND DISCUSSION}

The anti-animal trash bin was designed to not give space and the opportunity for long-tailed macaques to open. From Fig. 1, it can be seen that the height of the anti-animal trash bin is $92 \mathrm{~cm}$, its length is $46 \mathrm{~cm}$ and its width is $38 \mathrm{~cm}$. Even though the shape resembles conventional bins in terms of frame, structure and function, the design of the product has

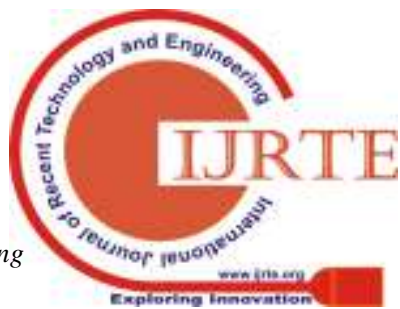


taken special attention on the opening and locking mechanisms so that the long-tailed macaques cannot open, while increasing their strength and durability to ensure the product's effectiveness.

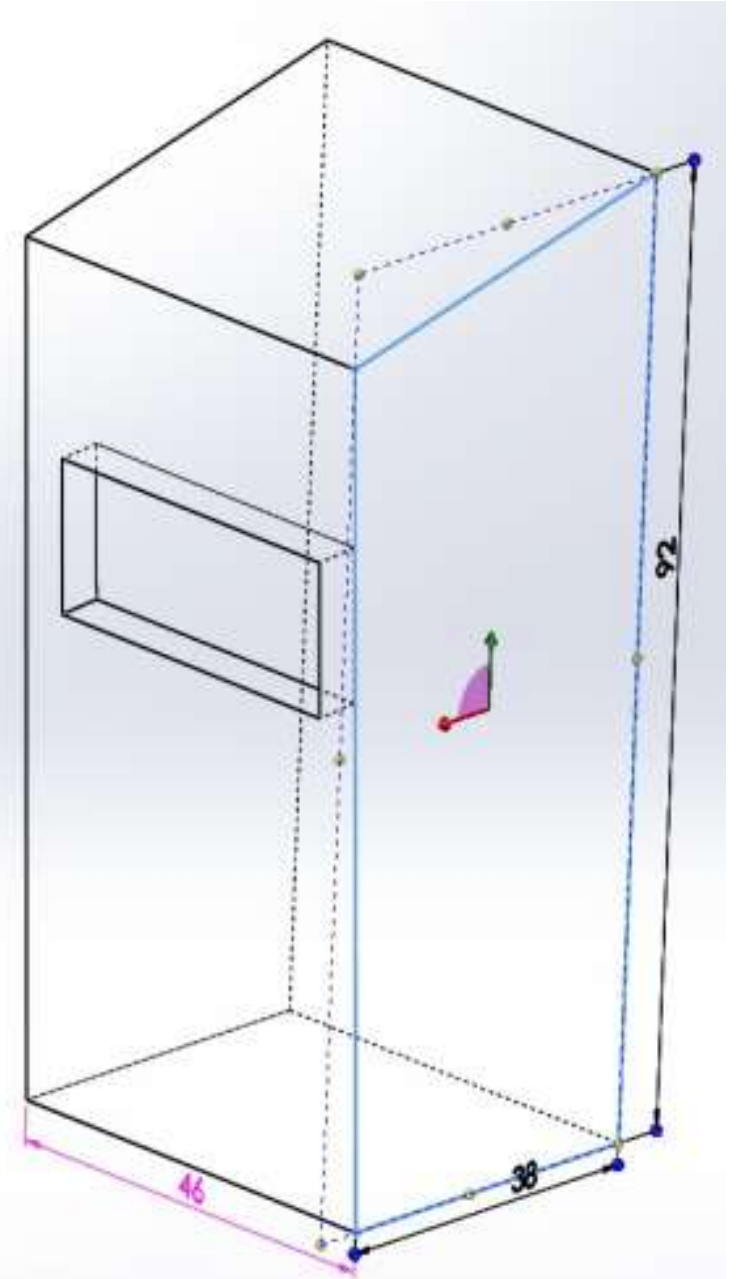

Fig. 1: 3D model of the anti-animal trash bin by using SolidWork software

Besides, the weight of this product is about $20 \mathrm{~kg}$ which is heavier than conventional bins. Weight plays a key role in stabilizing the product so that it does not fall easily when lifted by long-tailed macaques. Therefore, this product is made of steel compared to conventional which made from plastic. In addition to being heavy as it is made of steel, it is also stronger and durable. This product has a series of design mechanisms to prevent macaques from reaching and messing up waste. It consists of the opening of the cover at the top, the waste flow mechanism, the lock mechanism for the waste flow plate and the locking mechanism for the front door, upper and lower doors.

Fig. 2 shows 100 respondents' response to the anti-animal trash bin product features. Product features can be defined as the nature of the product that can fulfill the consumer's desire through the product, use and application of the product [12]. Almost all $(99 \%)$ respondents agreed that this product was very effective. This may be due to their own experience of seeing long-tailed macaques not being able to open an anti-animal trash bin cover. In addition to the experience, it is possible that the anti-animal trash bin design mechanism itself can convince users that long-tailed macaques are unable to open and disassemble the bin.

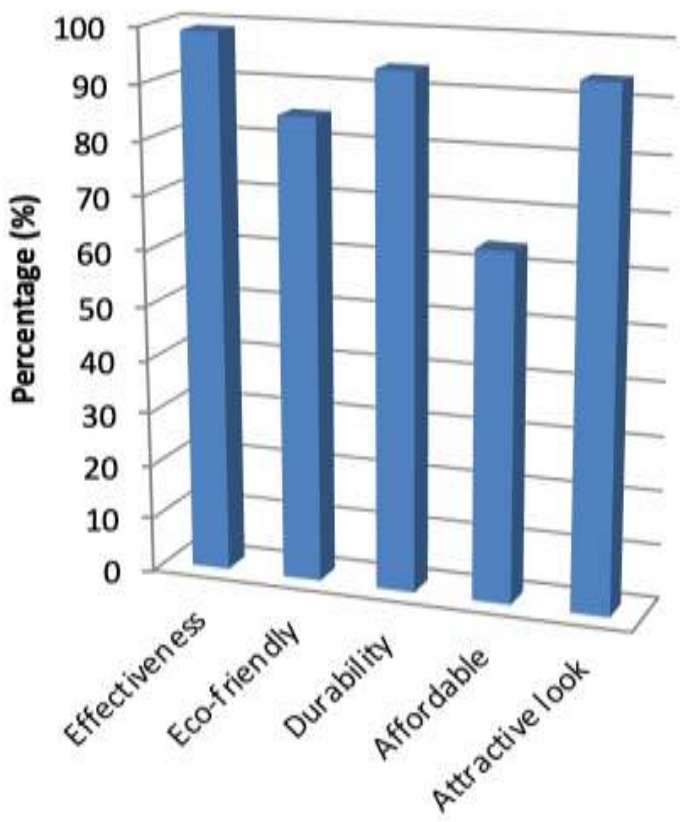

Product Features

Fig. 2: Respondent's feedback for the product features of anti-animal trash bin

Respondents also tend to agree that this product is environmentally friendly $(85 \%)$. To evaluate the environmentally friendly level of this product is based on how the product fits the environment without affecting the environment. Eco-friendly product development strategies are proactive and enable firms to quickly understand and adapt to increasingly volatile markets [13]. In addition, it does not cause any damage to the long-tailed macaques itself. The results of this survey also found that respondents agreed that the product had a very neat and attractive look (94\%). Respondents (94\%) believed in the durability of this product that it could last for a long time because of its manufacture of steel. However, this product needs to be monitored and repaired as it can be corrosive depending on the weather.

Of all the features, the ability to buy or own was the lowest in terms of user consent (64\%). This is because the suggested prices are quite expensive and less affordable for the general public, especially the lower income households. According to [14], the products (goods and services) must be in line with the expected customer benefit and the price corresponds to the potential buyer. Therefore, the target of selling this product is actually to the local authorities such as the District Council for placement in residential, commercial, and recreational areas. However, the price put on this product is reasonable, due to the fact that the material used, steel, is expensive in addition to the cost of manufacture. The choice of steel is to guarantee the strength, durability and stability of the product. However, there are suggestions for improvements to find cheaper materials to replace the original so that it is affordable for everyone. 
It is integral to the dynamic pricing strategy by continuously adjusting prices to meet their customers' characteristics and needs [15]. Fig. 3 shows an example of a prototype of an anti-animal trash bin that has been placed around Terendak Camp, Malacca for survey purposes.

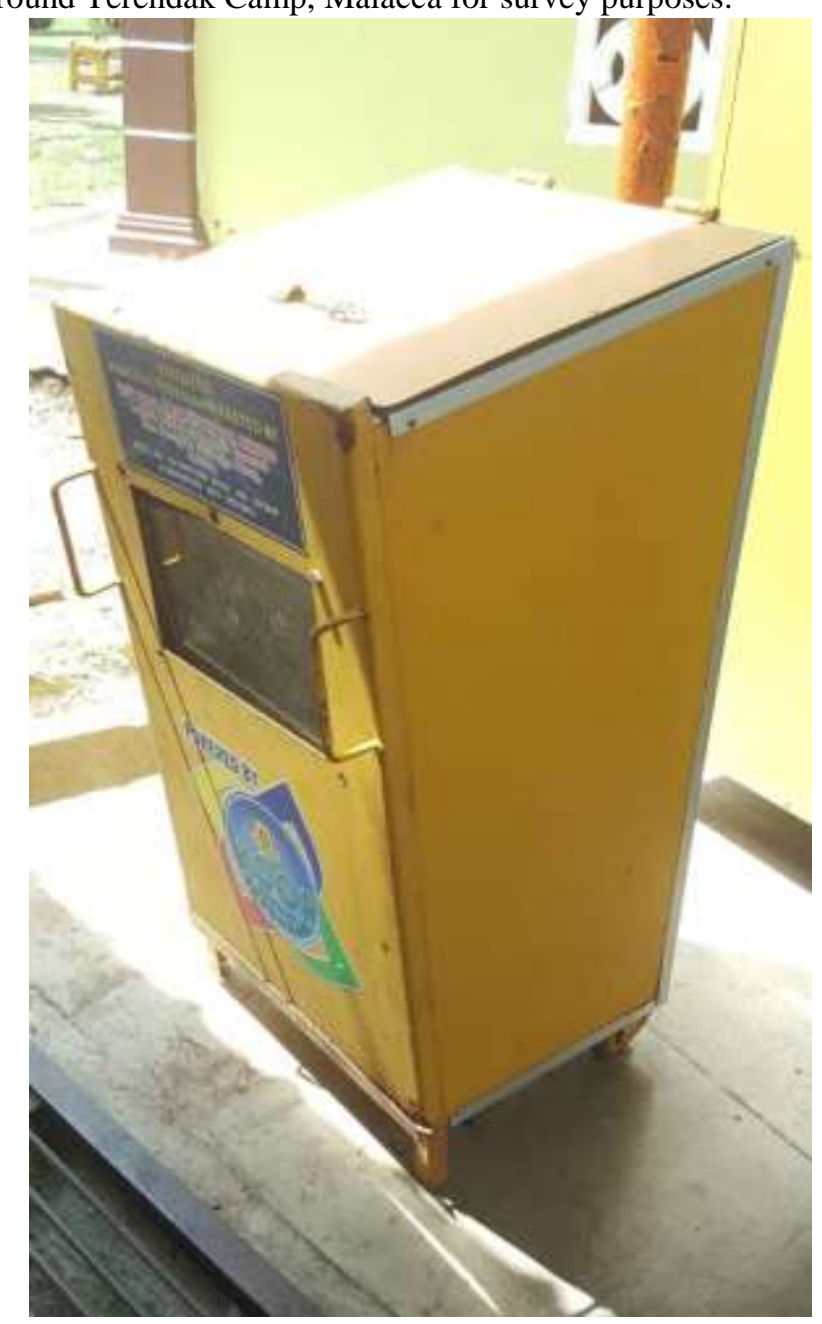

Fig. 3: Prototype of anti-animal trash bin

\section{CONCLUSION}

The objective of this study was to show an anti-animal trash bin drawing using SolidWork software to demonstrate its design features that prevent long-tailed macaques from opening it and to assess public perception of the innovation. The results of the survey found that the majority of respondents were very satisfied with the features of this product. We hope that the results of this study will convince the authorities and the buyer to use this anti-animal trash bin in areas that are often disturbed by long-tailed macaques.

\section{ACKNOWLEDGMENT}

We would like to thank the Faculty of Earth Science and the Faculty of Bioengineering and Technology, Universiti Malaysia Kelantan, Jeli Campus for providing the facilities in completing this study. Thanks also to the Mara Junior Science College, Terendak Camp, Malacca for providing the permits and accommodation during the study period. This study is an extension of the study of human-macaques conflicts previously funded by the Research University Grant Scheme (RUGS, UPM).

\section{REFERENCES}

1. J. Fooden, "Systematic review of Southeast Asian longtail macaques, Macaca fascicularis (Raffles, [1821]),' Fieldiana Zoology, 81, 1995, pp. 1-206.

2. B. P. Wheatley, R. Stephenson, and H. Kurashina, "The effects of hunting on the longtailed macaques of Ngeaur Island, Pulau," in The Nonhuman Primates, P. Dolhinow and A. Fuentes, Eds. California: Mayfield Publishing, 1999.

3. C. W. Marsh and W. L. Wilson, A Survey of Primates in Peninsular Malaysia Forests. Mal. Primates. Rec. Pgm., Selangor: Universiti Kebangsaan Malaysia, 1981.

4. S. Malaivijitnond and Y. Hamada, "Current situation and status of long-tailed macaques (Macaca fascicularis) in Thailand," Natural History Journal of Chulalongkorn University, 8, 2008, pp. 185-204.

5. A. M. San and Y. Hamada, "Reproductive seasonality of Myanmar long-tailed macaque (Macaca fascicularis aurea)," Natural History Journal of Chulalongkorn University, 9, 2009, pp. 223-234.

6. Jabatan Perlindungan Hidupan Liar dan Taman Negara (PERHILITAN), Pelan pengurusan kera (Macaca fascicularis) bermasalah di Semenanjung Malaysia. Kuala Lumpur: PERHILITAN, 2006.

7. K. Hambali, A. Ismail, B. M. Md-Zain, A. Amir, and F. A. Karim, "Diet of long-tailed macaques (Macaca fascicularis) at the entrance of Kuala Selangor Nature Park (anthropogenic habitat): Food selection that leads to human-macaque conflict," Acta Biologica Malaysiana, 3(2), 2014, pp. 58-68.

8. B. M. Md-Zain, M. R. Tarmizi, and M. Mohd-Zaki, "Campus monkeys of Universiti Kebangsaan Malaysia: Nuisance problems and students perception," in Monkey on the Edge, M. Gumert and A. Fuentes, Eds. England: Cambridge University Press, 2011, pp. 110-117.

9. K. Hambali, A. Ismail, S. Z. Zulkifli, B. M. Md-Zain, and A. Amir, "Human-macaque conflict and pest behaviors of long-tailed macaques (Macaca fascicularis) in Kuala Selangor Nature Park," Tropical Natural History, 12(2), 2012, pp. 189-205.

10. G. Engel and L. Jones-Engel, "The role of Macaca fascicularis in infectious agent transmission," in Monkey on the Edge, M. Gumert and A. Fuentes, Eds. England: Cambridge Universiti Press, 2011, pp. 183-204.

11. R. W. Sussman and I. Tartersall, "Behavior and ecology of Macaca fascicularis in Mauritius: A preliminary study," Primates, 22, 1981, pp. 192-205.

12. P. Kotler and G. Armstrong, Principles of Marketing. New Jersey: Prentice Hall, 2007.

13. C. S. Katsikeas, C. N. Leonidou, and A. Zeriti, "Eco-friendly product development strategy" Antecedents, outcomes, and contingent effects," Journal of the Academy of Marketing Science, 44(6), 2016, pp. 660-684.

14. L. Haghshenas, A. Abedi, E. Ghorbani, A. Kamali, and M. Harooni, "Review consumer behavior and factors affecting on purchasing decisions," Singaporean Journal of Business Economics, and Management Studies, 1(10), 2013, pp. 17-24.

15. D. O. Faith and E. Agwu, "A review of the effect of pricing strategies on the purchase of consumer goods," International Journal of Research in Management, Science and Technology, 2(2), 2014, pp. 88-102. 